\title{
Pilot Study: A Review of Personnel Involved in School Vision Screening and the Training Module in Betong, Malaysia
}

\author{
Nurul Farhana $A B^{\mathrm{a}}$, Chen $\mathrm{AH}^{\mathrm{a}}$, Abdul Rahim $M \mathrm{~N}^{\mathrm{a}}$, Goh PPb \\ a Department of Optometry, Faculty of Health Sciences, 17th Floor, Building FSK 6, Universiti Teknologi \\ MARA, 42300 Bandar Puncak Alam, Selangor, Malaysia. \\ ${ }^{b}$ Clinical Research Centre, Third Floor, Dermatology Block, Hospital Kuala Lumpur, Jalan Pahang, \\ 50586 Kuala Lumpur, Malaysia
}

\begin{abstract}
Introduction: School vision screening program is a scheduled program under the Ministry of Health, Malaysia for 7, 12 and 15 years-old children in the government schools. The aim of this study was to review the school vision screening program from the perspective of the personnel involved as the screener. Methods: The evaluation of the performance of the screener was based upon the accurate referrals' outcome from the school health database of Betong Division in Sarawak, Malaysia in the year of 2008. Results: The total accuracy of the referrals was $50.7 \%$. Lower accuracy of the referrals was found significantly associated with Grade $1\left[\mathrm{X}^{2}(2 . \mathrm{N}=304)=28.810, \mathrm{p}<0.001, \mathrm{OR} 4.472, \mathrm{Cl}_{{ }_{95}}=0.843=2.335\right]$ and among Native Iban $\left[\mathrm{X}^{2}(2 . \mathrm{N}=304)=\right.$ 7.901, $\left.\mathrm{p}<0.05, \mathrm{OR} 1.502, \mathrm{Cl}_{95}=0.935=2.414\right]$. Conclusions: Further review on the training modules demanded improvement and enhancement to suggest that training module might be one of the contributing factors on the performance of the screener.
\end{abstract}

KEYWORD: Vision, screening, primary schools, children, nurses, competency

\section{INTRODUCTION}

Different countries have different approaches on vision screening program involving children. ${ }^{1-3}$ In the United States, vision screening in children is recommended to be conducted at the age of six month old, preschool years (3-5 years old) and school years. ${ }^{1}$ There are differences regarding the guidelines, policies and procedures within the country dependent upon the state and locality. ${ }^{3}$ Nurses are commonly involved in vision screening for children..$^{4-8}$ The accuracy of vision screening conducted by nurses in Glasgow, United Kingdom was reported as $40 \%$, which indicated high over referrals despite the sensitivity and specificity of the vision test was high (83\% and 95\%). ${ }^{6}$ A 3-year evaluation of a pre-school screening program in Canada showed similar findings. ${ }^{7}$ Conversely, vision screening by school nurses in Oman showed higher accuracy of $85 \%{ }^{8}$

Corresponding author:

Nurul Farhana Abu Bakar

Department of Optometry, Faculty of Health

Sciences,

17th Floor, Building FSK 6,

Universiti Teknologi MARA, Puncak Alam Campus, 42300 Bandar Puncak Alam, Selangor, Malaysia.

E-mail: farhana_sb@yahoo.com

Telephone: 013-8185540

Fax: 03-32584597
A study on comparison of accurate referrals between orthoptists, nurses and general practitioners reported lowest false positive of approximately 1\% made by orthoptist compared to general practitioners (28\%) and nurses (34\%). ${ }^{9}$ The accuracy of vision screening assessment conducted by teachers or lay volunteers was uncertain dependent upon screening tests, and target population studied. ${ }^{10-12}$ Ophthalmologist and optometrists are rarely involved in vision screening assessment. One possible reason might be due to the shortage of qualified personnel and cost involved in producing screeners with professional degrees. In the Orinda study, vision screening by optometrist using modified clinical techniques (MCT) showed high accuracy of $89.5 \% .^{10}$ However, another study used the same method of MCT showed a reduction in the accuracy $(69.0 \%)$ probably due to inexperienced clinicians as it was conducted by optometry students. ${ }^{13}$

Routine child health programs and services are available under Ministry of Health, Malaysia since 1960s. ${ }^{14}$ In 1986, the National Standing Committee for the Prevention and Control Blindness was formed to formulate and coordinate eye care in Malaysia. Vision screening for children aged seven, 12 and 15 years old in the school health program is one of the highlight. ${ }^{15-16}$ Based on a study conducted in 2002, public awareness regarding vision care in this country was still unsatisfactory since about $57 \%$ of children with vision problems were found never had an eye examination. ${ }^{17}$ Still, there has yet to be any reported evidence of the effectiveness of the implemented vision screening system, which 
needs to be reviewed to improve service provision. There are several issues to consider regarding vision screening in children such as target condition and population for screening, suitable screening tools and the appropriateness of the screener. This study attempts to look into performance of personnel involved in the school vision screening. The training module was also reviewed as it might influence the accuracy of vision screening assessment. As a pilot study to evaluate the needs for major review of personnel involved, a vision screening program in Betong Division, Sarawak was selected to carry out the study objective. Betong Division was chosen because it is a rural area with no resident ophthalmic services available. Thus, an effective prevention of visual impairment and blindness in this division is highly reliant on the efficacy of the vision screening program.

\section{MATERIALS AND METHODS}

In order to assess the efficiency of the system for the school vision screening program, this study aimed to review the competency of the personnel assigned as the screener. This project adhered to ethical consideration based on Declaration of Helsinki 1975. The permission to conduct the training and school vision screening program was approved by Sarawak Department of Health. The performance of the nurses and assistant medical officers in the school vision screening was determined based upon the percentage of accurate referrals confirmed by comprehensive eye examination.

This was a retrospective study based on the data from the school health database of Betong Division in Sarawak, Malaysia in the year 2008. This data involves school children in Grade 1, Grade 6 and Form 3 from 105 primary schools and 12 secondary schools. The vision screening included monocular distance visual acuity test at 6 meters using Snellen notation visual acuity test conducted in 18 community clinics after two days of training. The official training for the screener (nurses and assistant medical officers) from Betong Division was first time conducted in November 2007. The training module included an 8-hour lecture presented by ophthalmologist and optometrist on the basic anatomy and physiology of the eyes, common vision problems in children, low vision in children and vision assessment procedures. Then, a 4-hour practical session was conducted to train the screeners to the exact procedures to conduct distance visual acuity tests.

The referral criterion was visual acuity (VA) of 6/9 or worse in either eye. Children who failed vision screening were referred for comprehensive eye examination, which was conducted by optometrists and ophthalmologists. Further vision assessment included refractive and binocular vision assessment as well as ocular health examination. Data entry and analysis was done using SPSS software, version 15.0 (Chicago, Illinois). Additional information on the association of the accuracy and ethnicity, gender and level of education were investigated using logistic regression. Ethnicity and age of the children were determined according to their birth certificates.

\section{RESULTS}

About $9.7 \%$ of the children failed in the screening and about $47.1 \%$ of them attended comprehensive eye examination (Table 1). The findings of comprehensive eye examination were known for 305 children. Complete data were unknown for 3 children due to either they defaulted follow-up or their medical records were incomplete. Review on the performance of the screener showed that the percentage of accurate referrals was $50.7 \%$. Information on the accuracy of thereferralsmadebynursesandassistant medical officers in school vision screening was shown in Table 2. Lower accuracy was found significantly associated with Grade $1\left[\mathrm{x}^{2}(2 . \mathrm{N}=304)=28.810\right.$, $\mathrm{p}<0.001$, odd ratio $\left.=4.472, \mathrm{Cl}_{.95}=0.843=2.335\right]$ and among Native Iban $\left[x^{2}(2 . N=304)=7.901, p<0.05\right.$, odds ratio $\left.=1.502, \mathrm{Cl}_{95}=0.935=2.414\right]$. No significant association in genders was found $(p>0.05)$.

Table 1: The outcome of school vision screening program in Betong Division for the year of 2008

\begin{tabular}{|c|c|c|c|c|c|c|c|c|}
\hline \multirow[t]{2}{*}{ Variables } & \multicolumn{2}{|c|}{ Grade 1} & \multicolumn{2}{|c|}{ Grade 6} & \multicolumn{2}{|c|}{ Form 3} & \multicolumn{2}{|l|}{ Total } \\
\hline & $\mathrm{N}$ & $(\%)$ & $\mathrm{N}$ & $(\%)$ & $\mathrm{N}$ & $(\%)$ & $\mathrm{N}$ & $(\%)$ \\
\hline No. of children screened & 2196 & $(100)$ & 2340 & $(100)$ & 2197 & $(100)$ & 6733 & $(100)$ \\
\hline $\begin{array}{l}\text { No. of children failed vision } \\
\text { screening }(\mathrm{VA}>6 / 9)\end{array}$ & 150 & $(6.8)$ & 160 & $(6.8)$ & 344 & $(15.7)$ & 654 & $(9.7)$ \\
\hline $\begin{array}{l}\text { No. of children attended } \\
\text { comprehensive eye } \\
\text { examination }\end{array}$ & 58 & $(38.7)$ & 118 & (73.8) & 132 & $(38.4)$ & 308 & $(47.1)$ \\
\hline
\end{tabular}


Table 2. The accuracy of the referral made by nurses and assistant medical officers in school vision screening in Bentong Division

\begin{tabular}{lllll}
\hline Variables & Total $(\mathbf{N})$ & Accuracy $(\%)$ & Odds ratio & P Value \\
\hline $\begin{array}{l}\text { Ethnicity } \\
\quad \text { Chinese }\end{array}$ & 17 & 76.5 & & \\
$\quad$ Iban & 171 & 45 & & \\
$\quad$ Malay & 116 & 55.2 & 1.502 & $0.019^{*}$ \\
Gender & & & & \\
$\quad$ Male & 101 & 45.5 & & \\
$\quad$ Female & 203 & 53.2 & 1.359 & 0.208 \\
Level of Education & & & & \\
Grade 1 & 58 & 20.7 & & \\
Grade 6 & 116 & 62.1 & & \\
Form 3 & 130 & 53.8 & 4.472 & $<0.001^{*}$ \\
\hline
\end{tabular}

\section{DISCUSSIONS}

The accuracy of the referrals in this study was relatively low, similar to the previous studies to support that vision screening by nurses have the tendency for higher over referrals. ${ }^{6-7}$ High falsepositive referral indicates unnecessary referral, which may increase the cost and lead to higher workload in secondary care level. Alternatively, high accurate referrals by nurses in Oman suggested that the accuracy of vision screening assessment could be improved by proper training. ${ }^{8}$ As supported by earlier study, the accuracy of vision screening assessment might be influenced by experience and competency of the screener. ${ }^{13}$

Although orthoptists may be more skilled in detecting vision disorders in young children compared to other personnel, $6,7,9$ their numbers are limited in Malaysia. Because of limited numbers, orthoptists are not involved in the school vision screening. The involvement of teachers as vision screeners may not be appropriate although their numbers are quite high due to high workload with teaching and administrative tasks. ${ }^{18}$ Besides, teachers should focus more on education rather than health issue. The participation of nurses and assistant medical officers may be more practical and costeffective in Malaysia since they are already a part of health system.

Low attendance rate in comprehensive eye examination $(47.1 \%)$ might be a limitation on the evaluation of the accuracy in this study. However, it provides information on cultural competent of the vision care system in Malaysia, which is important as a multi-racial country. Besides, lower accurate referrals among native iban indicate that referrals might be associated with the ethnicity of the patient. ${ }^{19} \mathrm{~A}$ language barrier between the examiner and the patient can affect the vision screening accuracy. However, due to limited information gained from this study (as it assessed native iban and non-iban only), these findings need further investigation on the culturally competent vision care system in Malaysia to alleviate the disparities related to the ethnicity and socioeconomic disadvantages.

Lower accurate referrals among children in Grade 1 compared to children in higher grades indicate the importance for the screener to understand more on children's visual behavior. As communication difficulty and problems in recognizing letters were found to contribute to low accuracy of visual acuity test in a younger age group, it is suggested that age-appropriate test could be useful addition in the vision screening tool. The use of a non-verbal test such as letter-matching or picture-matching test may increase the accuracy of the vision screening assessment. ${ }^{7,20}$ However, it should correspond to the training module as lack of training could lead to misinterpretation of the results and reduced the accuracy of the vision screening test.

Due to low accuracy of the referrals found in this study, a review on the training module was made according to the performance of the screener to achieve the suggested goals of school vision screening program based on the outcome. The review suggested that the training moduleneedimprovementandenhancement. The outcome-based education is "a process that involved restructuring of curriculum, assessment and reporting the practices in education to reflect theachievement of high-order learningand mastery rather than accumulation of course credits". ${ }^{21}$ Based on the concept, the training process directed at achieving specific outcomes, which should be developed by the 
trainees at the end of the training program. On the other hand, the training structures and the module should be evaluated for continuous quality improvement. ${ }^{22}$ The approach is according to four principles of the clarity of focus, design down, high expectations and expended the opportunities. ${ }^{23-24}$ It was widely used in academic areas, and the application of this concept is also practical for planning and designing atrainingmoduleformedical professions. ${ }^{25}$

We reviewed the training module and discussed the four areas according to the outcome-based education principles. First, the clarity of focus: the module was found not designed to prepare the screener towards achieving the objective of the program. The planning for the module did not tally with the practice of vision screening assessment. Even though the screeners were taught to identify more vision disorders in their training, the referral criterion for vision screening, however, was only based on visual acuity assessment outcome. This situation reflected that the screeners actually learned more than what they actually do. Second, design down: the design of the module did not clearly define the outcome of the school vision screening program that screeners are to achieve by the end of their training. Evaluation on the contents of the lectures found that the screeners were not informed of the objectives and outcomes of the program and what are expected from them in order to achieve the outcomes. There was no lecture, specifically on school vision screening to educate them about the importance and the implementation of the vision screening program, including the referral system and other related topics. Third, high expectation: the training module does not establish a standard of the performance for the screener to improve their competency. There were no assessments conducted before, and after the training program or re-assessment was planned during the screening program. Fourth, expended opportunities: therewas no evaluation on the effectiveness of the training to provide learning opportunities matched with the suggested goals of school vision screening program.

\section{CONCLUSION}

The involvement of the nurses and assistant medical officers in school vision screening is practical in Malaysia despite low accuracy of the referrals. As supported by the literature, the accuracy could be improved by proper training. A revision on existing training module should take into consideration the age and ethnicity of the target population and the type of the vision test used in screening.

\section{Declaration of Conflicting Interests}

The authors declared no potential conflicts of interest with respect to the authorship and/or publication of this article.

\section{Acknowledgement}

We would like to thank the Director General of Health of Malaysia for the permission to publish this paper, and all staffs from Department of Health of Betong and Sri Aman Division for their assistance in this study.

\section{REFERENCES}

1. A Joint Statement of the American Association for Pediatric Ophthalmology and Strabismus and the American Academy of Ophthalmology. Eye examination in infants, children, and young adults by pediatricians 2003; Reaffirmed May 2007.

2. Child Health Promotion Programme (UK) 2008.

3. Ciner EB, Dobson V, Schmidt PP, et al. A survey of vision screening policy of pre school children in United States. Surv Ophthalmol 1999;43:445-57.

4. Cummings GE. Vision screening in junior schools. Public Health 1996;110:369-72.

5. Chui L, Fraser T, Hoar K, LaRoche GR. Negative predictive value of a vision screening program aimed at children aged 3 to 4 years old. J AAPOS 2004;8:566-70.

6. Khandekar R, Al Harby S, Abdulmajeed T, Helmi SA, Shuaili IS. Validity of vision screening by school nurses in seven regions of Oman. East Mediterr Health J 2004; 10:528-36.

7. Spowart KM, Simmers A, Tappin DM. Vision testing in schools: an evaluation of personnel,tests, and premises. J Med Screen 1998;5:131-2.

8. Robinson B, Bobier WR, Martin E, Bryant L. Measurement of the validity of a preschool vision screening program. Am J Public Health 1999;89:193-8.

9. Edwards RS, Whitelaw AJ, Abbot AG. Orthoptist as pre-school screeners: a 2-year study. Br Orthop J 1989;46:14-9.

10. Blum HL, Peters HB, Bettman JW. Vision screening for elementary schools; the Orinda study. Berkeley. University of California Press 1959.

11. Khandekar R, Parast N, Arabi A. Evaluation of 'vision screening' program for three to six-year-old children in the Republic of Iran. Indian J Ophthalmol 2009;57:437-2.

12. Mozlin R. The epidemiology of school vision screening. J Behav Optom 2002;13:59-65.

13. Bailey N. Assessing the predictive ability of the test-positive findings of an elementary school vision screening. Optom Vis Sci 1998;75:682-91.

14. Mohd Kassim AB. MOH Programme and Initia tive to Detect for Disability in Children, Family Health Development Division, Ministry of Health. The First National Early Childhood Intervention Conference, 
18-20 November 2006, Penang.

(unpublished paper)

15. Ismail S, Samad MI, Omar AZ. Blindness

prevention and control programme in

Malaysia. NCD Malaysia 2002;1:18-21

16. Family Health Development Division, Department of Public Health, Ministry of Health Malaysia, official website copyright 2007.

17. Teoh SC, Chen AH. Kajian mengenai tahap kesedaran penjagaan penglihatan terhadap kanak-kanak. Jurnal Kesihatan Masyarakat Isu Khas 2002:60-65.

18. Boey EK. Teacher Empowerment in secondary schools: a case study in Malaysia. Germany: Herbet Utz Verlag, 2010.

19. Anderson LM, Crimshaw SC, Fullilove MT, Fielding JE, Normand J; Task Force on Community Preventive Service. Culturally competent healthcare systems a systematic review. Am J Prev Med 2003;24:68-79.

20. Schmidt $P$, Maguire $M$, Dobson V, et al. Comparison of preschool vision screening test administered by licensed eye care professionals in the Vision Preschoolers Study. Ophthalmology 2004;111: 637-50.

21. Tucker B. Literature review: outcomefocused education in universities. Learning support network. Curtin University of Technology 2004.

22. Training manual module 3 : the planning and design outcome-based learning. South African Management Development Institute (SAMDI) 2007.

23. Spady W. Outcome based education: critical issues and answers. American association of school administration: Arlington, Virginia 1994.

24. Killen R. Outcome-base education: principles and possibilities. Unpublished manuscript. University of Newcastle, Australia: Faculty of Education 2000.

25. McNeil HP, Hughes CS, Toohey SM, Dowton $\mathrm{SB}$. An innovative outcome-based medical education built on adult leaning principles. Med Teach 2006;28:527-34. 